\title{
Considering 3D-objects within a 2D hydraulic modelling approach of pluvial flooding events \\ Matthias Stork ${ }^{1, a}$, André Assmann ${ }^{1}$ \\ ${ }^{1}$ geomer GmbH, Im Breitspiel 11B, 69126 Heidelberg, Germany
}

\begin{abstract}
The production of pluval flood hazard maps have became increasingly important in recent years. In contrast to fluvial flood hazard modelling a more detailed consideration of small surface structures and permeable structures have large relevance for pluvial hazard simulation, because they have a significant influence to runoff processes. Additionally, infrastructure facilities like bridges, tunnels and even large individual buildings are of particular importance, when drainage take place on several height levels which might be connected with each other. Commonly, hydraulic 2D models only allow one level of flow, therefore individual solution approaches have to be developed. Three examples will be elaborated in this paper how model design can meet such requirements in practice. The examples are taken from pluvial flood risk management projects in different regions of Germany, also considering various data availability and quality.
\end{abstract}

\section{Introduction}

In recent years, several heavy rainfall events have caused severe damages on people, infrastructure and private property in different parts of Germany (i. a. Dortmund 2008, Ditzingen 2010, Braunsbach and Wadern 2016). Additionally, climate projections suggest an increase in frequency and intensity of torrential storm events in future (Fallmann, et al. 2017, DWD 2016). This brings in focus the need for pluvial flood risk modelling into the focus of public hazard risk management.

Thus, pluvial flood hazard maps have become of increasing relevance in flood risk management in recent years. However, modelling requirements differ in many aspects from those of river flood risk maps. Discharge concentrations and runoff processes at small-scale catchment area level are significantly altered by small surface structures such as buildings, walls and in certain areas even kerbstones and their consideration are crucial for the analysis of flow paths. Additionally, large infrastructure facilities like bridges, tunnels and underpasses are of importance, because they work like flow connections between two places that would topographically not be in direct connection with each other. Drainage may take place even on several levels simultaneously at the same place.

Common 2D models only allow one level of flow. Even the integration of a sewer network via a coupled sewer network model, which is supported by some models, will hardly cover all requirements of pluvial flood hazard modelling. Surface discharge processes on several levels are usually not covered by these models so far. The aim of this paper is to demonstrate different approaches how to deal with those issues in practice. For runoff modelling the raster-based hydraulic 2D model FloodArea ${ }^{\mathrm{HPC}} 11$ was employed (geomer 2017).

\footnotetext{
${ }^{a}$ Corresponding author: matthias.stork@geomer.de DOI 10.3311/FLOODRisk2020.9.2
}

\section{Modelling approach}

The production of pluvial flood risk maps and the subsequent risk management process in Germany is not uniform between the federal states, since torrential rain risk management is still a young process. Basis for hydraulic simulations is the hydrology, which provides spatial information about the part of perception that comes to runoff (runoff coefficients). Only the federal state of Baden-Württemberg was setting standards with providing state wide runoff data on $5 \mathrm{~m}$ resolution level which are committed for 2D hydraulic flood hazard modelling (LUBW 2016 and Steinbrich et al. 2016). For pluvial flood risk projects in other federal states the hydrology has to be provided individually by the assigned company or institution. In those projects a 3-step process was applied:

\section{Precipitation model (rainfall input):}

The amount of rainfall and its temporal distribution are important parameters for the dynamically varying surface runoff. A typical scenario for pluvial flood hazard modelling is a precipitation event that lasts for $60 \mathrm{~min}$ and an additional 120 minutes of further runoff. Total rainfall volume depends on the desired scenario and can be a statistic value like a rainfall event with a 100 -year return probability or a synthetic event (e.g. $60 \mathrm{~mm} / \mathrm{h}, 90 \mathrm{~mm} / \mathrm{h}$ and $120 \mathrm{~mm} / \mathrm{h}$ ).

\section{Hydrologic model (infiltration):}

In order to simulate infiltration and surface runoff on spatial scale, the hydrological model Hydro ${ }^{\text {RAS }}$ was used. This model calculates time variant runoff coefficients (geomer 2018). The input data precipitation, soil, land use and high-resolution terrain data are processed in a data base following the approach of the regionalisation process of Lutz (1984) combined with the simplified infiltration approach from Dyck and Peschke (1989, 1995). The resulting coefficients are varying during the hyetograph for instance when the soil water storage is getting saturated and infiltration rates are decreasing. The result is a set of 
runoff coefficient rasters with previously defined time steps.

Hydrologic model (runoff concentration/backwater): Here, the raster based $2 \mathrm{D}$ model FloodArea ${ }^{\mathrm{HPC}} 11$ was used for hydraulic runoff simulation. It relies on a simplified approach based on the hydraulic formula of ManningStrickler that makes it capable to simulate large areas with high resolution data within an acceptable and realistic time frame. Required input data are runoff coefficients, rainfall hydrograph surface roughness and a high resolution DTM (Digital Terrain Model).

High resolution terrain data is essential for model quality in urban areas, since it is possible to consider the effects of small structures and small-scale slope changes on runoff concentration processes, flow paths and flow velocities accurately.

During the validation process missing surface structures, like buildings, will be implemented into the DTM using a GIS software. However, there are features, which cannot be represented by a DTM, because of its 2D nature. These are for instance culverts, outlets of retention basins or underpasses etc. Most of these features can be implemented by pumping functionalities within the FloodArea ${ }^{\mathrm{HPC}} 11$ model system. In principal the pumping functionality works in the way that a start-coordinate (x1, $\mathrm{y} 1)$ and a target-coordinate (x2, y2) has to be specified. The water transfer then takes place according to a given discharge capacity.

The simulation results shown in this paper represent inundation depths as maximum flood depth of all-time steps within the entire simulation time frame for each grid cell. Although the simulated minimum value for water depth is $1 \mathrm{~mm}$, the lower threshold water depth value is $3 \mathrm{~cm}$ for display in this paper.

\section{Case studies}

Three examples are taken from pluvial risk management projects in different regions of Germany. Use cases can be distinguished into the following categories:

(i) Artefacts of DEM and objects that are affecting flow path crucially (e. g. walls kerbstones or bridges): That can be flow connections, blocking and redirection of pathways. Depending on their shapes and characteristics an appropriate level of detailing is therefore needed (Chapter 3.1).

(ii) Infrastructure with complex hydraulic conditions: This can be large buildings (i.e. railway stations) with flow paths on several levels, often crossed by traffic routes (roads, railways) and flow paths occur partly subterraneous. They may have large roof areas and possibly parking decks. These buildings must be assessed with regard to their relevance and then broken down into different levels of flow. These levels need to be modelled separately but must be interactively linked with each other (Chapter 3.2).

(iii) Permeable structures and buildings: Buildings with passages can either be open or closed: Here, it is important to decide on a specific scenario, because that may make a big difference for the risk assessment results (Chapter 3.3).

\subsection{Artefacts of DEM features}

Digital terrain data in Germany for torrential rain hazard modelling is usually provided by federal state offices for geoinformation. They are products of airborne LiDAR (Light Detection And Ranging) measurement campaigns and typically stored in LAS data format. During their production LAS (Lidar Archive Standard) data is subject to a classification and filtering process. Outcomes of LiDAR measurements can be distinguished mainly into two types of digital elevation models (DEM): First, a DSM that corresponds to the first returns of the LiDAR three-dimensional point cloud like ground, vegetation, infrastructure and buildings; and second the digital terrain model (DTM) that considers the last returns that fits the bare earth surface (Parrot \& Ramírez-Núñez 2015). However, the last returns do not always reach the bare earth surface when the radar beam hits an obstacle.

For hydraulic modelling DTM data have to be preprocessed. Since some infrastructure features, like bridges often still remain in DTM, these artefacts block flow paths in hydraulic modelling. However, some removed bridges have to be reintegrated by supplementing them from digital surface model (DSM) data, or by interpolation methods. Thus in some cases, they represent important flow path connections on real conditions. A missing of these connections would lead to misdirected runoff to other places with erroneous water depths and flow velocities downstream.

Figure 2 shows both situations in the city of Ulm, Baden-Württemberg, south of Germany, where runoff takes place mainly on two levels. A railway viaduct is crossing a road that is leading south-eastwards. This road itself is crossing another railway track. Under real conditions water flows from northwest beneath the railway viaduct and further crossing the bridge southwards (first level). Water on the bridge is principally kept by kerbstones on the street. Water that flows along the railway tracks is flowing freely under the bridge from the west to the east (second level).

Without DTM pre-processing, artefacts are causing backwater situations on the railway tracks and north of the viaduct on the one hand and a redirection of runoff from the street to the tracks on the other hand (Figure $2 \mathrm{a}$ and $\mathrm{b}$ ). This leads to significant reductions of southward water flow and probably to false flood risk assessments downstream the road bridge. One approach to resolve this situation was to remove the artefacts and reintegrate the bridge (incl. kerbstones) by using various ArcGIS processing tools. The runoff on the railway tracks was ensured by pumping functionalities within FloodArea ${ }^{\mathrm{HPC}} 11$. 

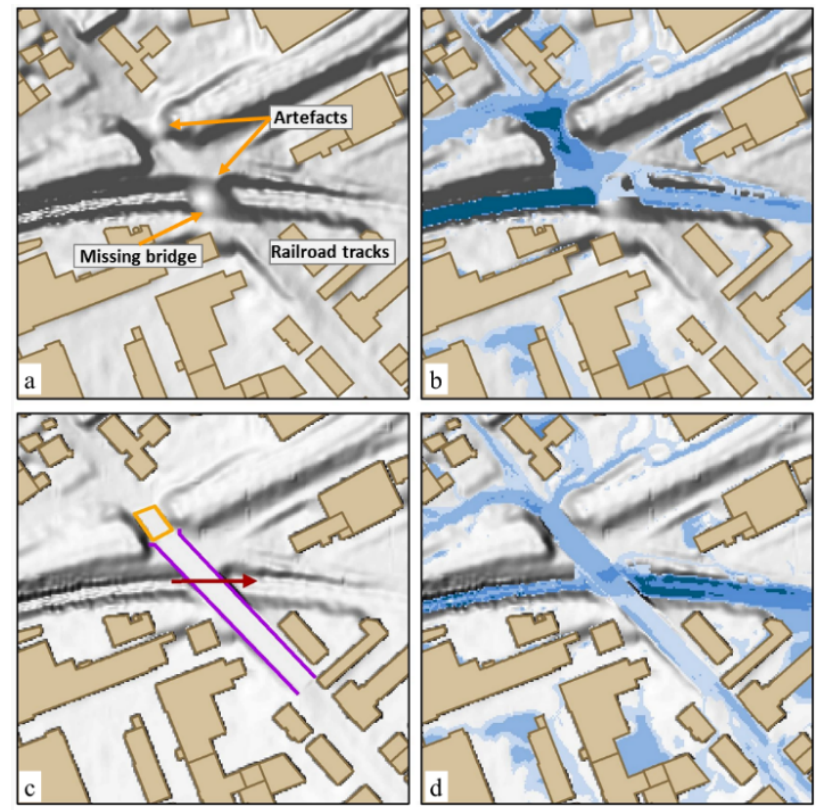

Flood depth $(\mathrm{cm})=3-10=10-50=50-100 \square>100$

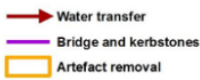

Figure 1. Artefacts of structure removals hinder a free runoff during hydraulic simulation in Ulm (Germany) ( $a$ and $b$ ) compared to a modelling with a processed DTM (c and d)

Figure 2 (c and d) shows the modifications and the model quality improvement. All relevant connections could be established. It is noticeable, that water depths on the eastern tracks are larger than on the western side. This is due to large discharge capacities because of a high hydraulic radius of the railway tracks. This leads to a kind of inlet funnels at the starting coordinate grid cell and to discharge funnels at the endpoint grid cell when more water arrives than can immediately discharge downstream.

\subsection{Infrastructure with complex hydraulic conditions}

Occasionally, pluvial flood hazard modelling has to deal with quite challenging situations. This is especially true for infrastructures in urban areas with flow processes that take place on several levels, subterranean flow paths may be connected with each other and energy gradients are ambiguous. These conditions require a lot of effort to warrant sufficient model quality, especially when using a raster-based model like FloodAreaHPC11, which calculates runoff on a surface level.

An example for infrastructure with complex hydraulic conditions is the railway station Willhelmshöhe in Kassel, Hesse, central Germany. The station is an important traffic junction for both national railway and local urban traffic network. Therefore, good modelling results were particularly important and an individual modelling design was developed.

The principal drainage situation with flow paths shown in Figure 2. Blue arrows indicate open runoff at the surface, in the following referred to as surface level flow. The dashed red arrows show flow paths which are subterranean, designated as subsurface level flow. The railway station is situated in a topographic depression. So, water that flows on the street parallel to the tracks or on the tracks is concentrated within the road underpass or on the tracks within the station building. Making the situation even more complex, open passages at a height of $50 \mathrm{~cm}$ above ground level within the road underpass are connecting the road and railway tracks with each other. Most of the runoff is coming from the west and flows either over the station forecourt or branches off into the street to the north and then further into the road underpass or further northwards. Water that enters the road underpass from the south comes from the living quarters in the west or from the parking deck.

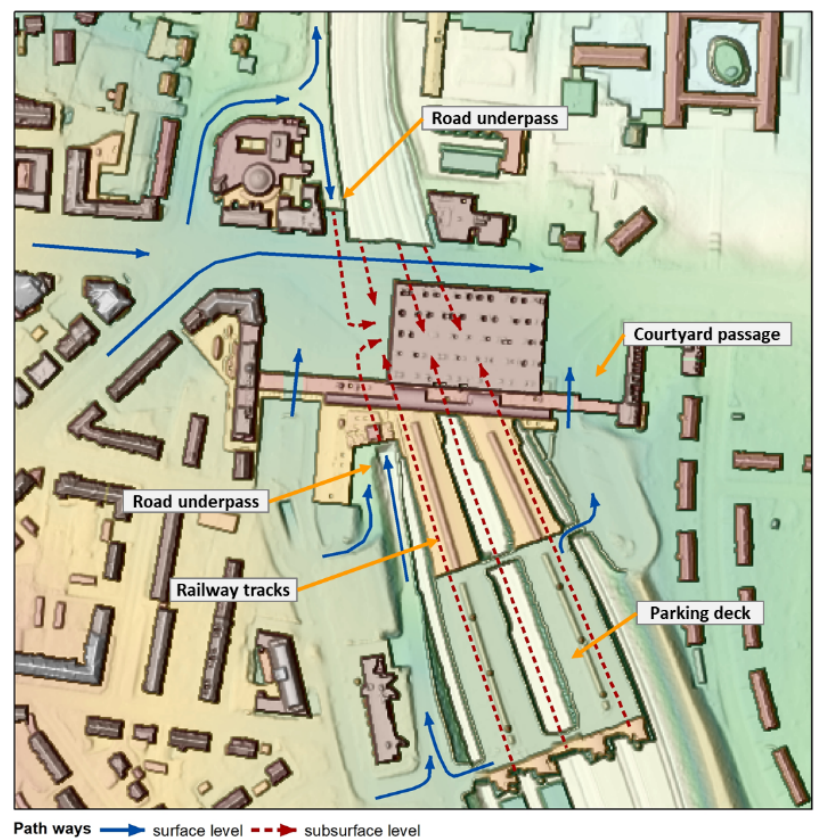

Figure 2. Principal flow path conditions on different levels at railway station Kassel Willhelmshoehe.

Running a raster-based model under standard operation leads to backwater and overflow situations north and south of the road underpass as well the railway tracks. Therefore, the hydraulic energy lines are not balanced, which leads to incorrect water levels in the areas mentioned.

The applied modelling approach was to separate the surface level from the subsurface level by using two models, which are connected by pumping connections with each other. The model setup was as follows:

- First model: Runoff simulation of the entire catchment area on surface level (surface level flow).

- Second model: Runoff simulation only of the subsurface level and the railway tracks in the area of the railway station (subsurface level flow).

Therefore, a section of the first model was copied and shifted outside the first model extend Figure 3_( $a$ and $b$ ). This was done for the DEM ${ }^{\mathrm{a}}$ and the roughness raster. For

\footnotetext{
${ }^{\mathrm{a}}$ In this project a hybrid form of DTM and DSM was used with the bare surface of the DTM and buildings fron the DSM. Thus it is rather an DEM than a DTM.
} 
the runoff coefficient rasters it was important to use only the extend of the subsurface level and the railway tracks in the second model and not in the first model to prevent double precipitation input into the system. These rasters were cut out of the first model and then shifted into the extend of the second model. In total twelve runoff coefficient rasters representing each 5 min out of a $60 \mathrm{~min}$ hydrograph were modified like this.

Next step was to establish the water transfer from the first to the second model for all the water that would discharge into the subsurface level of the first model Figure 3 (c and d). That was achieved by using about 150 pumping connections as described above with limitless discharge capacity. The large number of connections was necessary due to the $1 \mathrm{~m}$ DEM resolution and the requirement that no water falls through the mesh and is getting lost for the second model.
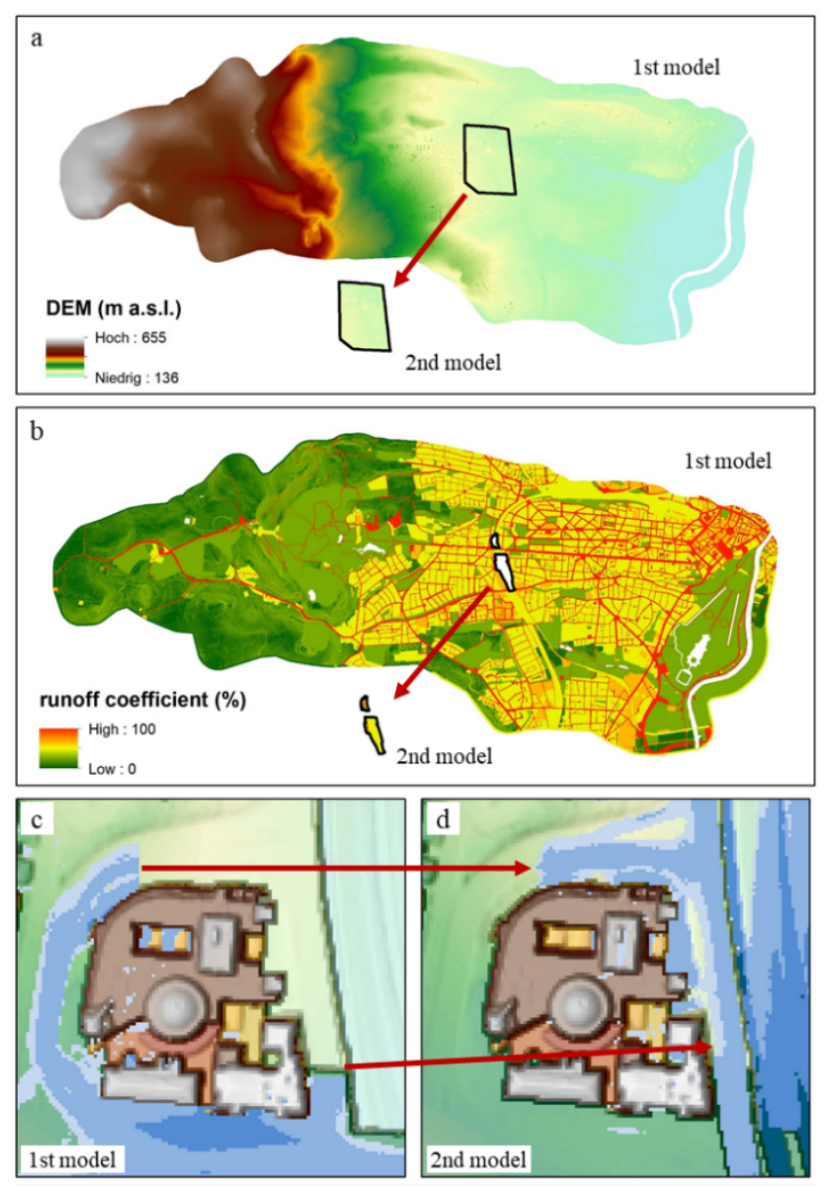

Figure 3. Development of a first and a second model for hydraulic simulation for the DGM (a) and a sample discharge coefficient raster for one time step (b) as well as water transfer between the two models during simulation ( $\mathrm{c}$ and $\mathrm{d}$ ).

One fact that made it easier was that the subsurface level in the second model could be defined as a closed system, because of the trough situation of the subsurface level. No water could leave the area of the tracks and the underpass back to the first model. Only the runoff northwards on the street parallel and westward surface level runoff from the parking deck was transferred back to the first model by using pumping connections (Figure 2).
The last step before running the final simulation run was to modify the second model DEM by using 3D extension tools from Esri ArcGIS. In the area of the road underpass survey data from the municipal land surveying office were provided with absolute heights for the road surface and the passages. Unfortunately, no survey data for the railroad tracks were available and no access permitted. Thus, heights had to be interpolated from the DEM heights between northern and southern tracks. Figure 4 (a and b) shows the original situation and the DEM after modification. The magenta coloured lines are polygons which contain z-values in metre above sea level. The interpolation distance was varying between the railroad tracks, because some tracks were open without a covering roof other are covered with the parking deck.

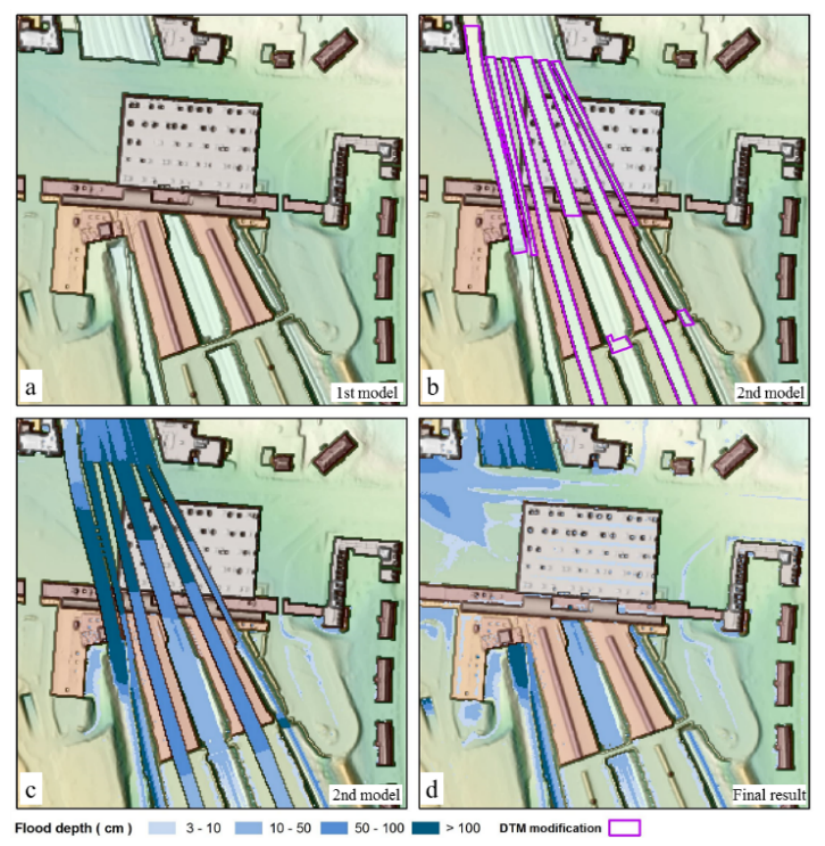

Figure 4. This figure shows the original DEM used for the $1^{\text {st }}$ model (a), the implementation of subsurface level pathways into the $2^{\text {nd }}$ model (b), maximum inundation depth in the $2^{\text {nd }}$ model (c) and the joint results of $1^{\text {st }}$ and $2^{\text {nd }}$ model.

Figure $4 \mathrm{c}$ depicts inundation depth results from the second model. Water that was within the road underpass could enter the track body and distribute there when water levels were high enough to cross the passages. The hard changes of displayed water levels within the interpolated tracks are due to changes in the classification symbology. Water levels between the north and the south could be balanced successfully.

For final hazard mapping, the results from both models were brought together. First, all inundated areas within subsurface level of the second model with covering infrastructure atop were blanked out by using the polygons shown in (Figure $4 \mathrm{~b}$ ). Hereinafter, the remaining inundation areas were shifted back to their original position and merged with first model results (Figure $4 \mathrm{~d}$ ).

With this approach it was possible to consider all relevant levels of flow and produce adequate pluvial flood hazard maps. There might still be inaccuracies in model quality because of the interpolated railway tracks and the 
non-availability real survey data. However, it is the best possible approximation to the circumstances.

\subsection{Permeable structures and buildings}

In year 2016 a heavy rainfall event with about $60 \mathrm{~mm}$ precipitation in short time caused major damages in Wadern, Saarland, southwest Germany. Hereafter, a pluvial flood risk assesment was conducted including the development of risk maps. For this project a DTM in the way described above was used. Buildings were integrated by lifting up the terrain by $5 \mathrm{~m}$ at places with house footprints. The footprints were taken from public land use data (BKG 2017 and LVGL 2015).

In a municipal park in Wadern the simulation results show an area of extensive backwater due to the path way blocking effects of houses in the east of the park (Figure 5 a). Houses are integrated into the DTM as solid, nonpermeable blocks. This leads to increased inundation depths and lateral flow towards the south. During a validation survey on site, the owner of a butchery stated that they opened the doors during heavy rainfall events in 2016 so that the water could flow through their shop without causing any serious damage (Figure $5 \mathrm{~b}$ ).
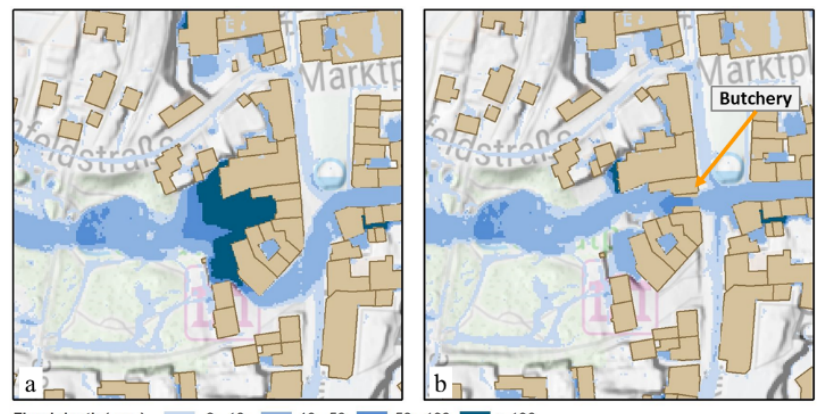

Figure 5. This figure shows the simulation results for inundation depth for two different scenarios with an open (a) and closed (b) passage through the building front.

Thus the question arises, what scenario should be taken for risk assesment? A scenario definition with closed doors lead to backwater and large inundation depths (here up to $4.5 \mathrm{~m}$ for the $90 \mathrm{~mm}$ precipitation scenario) and represents worst case for the affected houses. On real conditions these water depths are unlikely, because they would lead to massive water pressure causing most propbaly heavy damage to weak points in the facade of houses (i.e. pushing in windows, doors and unstable walls). This senario would have great impact to the houses and the people living in there. A scenario definition with open doors and free runoff may be more realsitic on the one hand, but may lead to an underestimation of risk potential and a false risk assesment on the other hand.

This case in Wadern is of cause a special situation, but it makes clear what effects scenario definitions can have and that a clear scenario definition with the clients is important.

One addional aspect in this category is walls that are made of permeable materials. In fluvial flood hazard modelling in germany these structures are not considered. However, for pluvial flood hazard modelling permeable structures can have deflecting and redirecting effect on flow pathes. This implies that also already existing evaluations of structures must be re-evaluated and, if necessary, supplemented depending on the event type considered.

\section{Conclusions}

Every use case is unique because every location is different. If the normal processes are not working, individual solutions must to be developed. Usually, several options are available to cope with the specific situation and compromises have to be made (model accuracy, data availability, scenario definition, cost-benefit etc.).

When topography is not ambiguous, pumping connections can provide a solution like in the case of Ulm (chapter 3.2). However, this work-around does not fit for ambiguous discharge situations like in Kassel. Here a detailed examination and the integration of a more complex model design can be necessary or even unavoidable, since the results can also affect the wider environment.

All of these three examples show that a first simulation run is crucial for the validation of DTM datasets and the quality of simulation results and pluvial flood risk maps. The example case of Wadern showed, that on-site validation surveys can have great impact on model quality, because without validation and contact with stakeholders, there would have been no information on real local conditions and requirements on a possible scenario adaption.

\section{References}

1. Anders K., Assmann A. \& Fritsch K. (2016). Prospects and requirements for an operational modelling unit in flood crisis situations. In: 3rd European Conference on Flood Risk Management (FLOODrisk 2016), E3S Web Conference, 7 p.

2. Assmann A., Krischke M. \& Höppner E. Risk maps of torrential rainstorms. In: P. Samuels, S. Huntington, W. Allsop, \& J. Harrop, eds. Flood risk management: research and practice, 2009, 49, Taylor \& Francis Group, London.

3. Bundesamt für Kartographie und Geodäsie (BKG) (2017). www.sg.geodatenzentrum.de/web_public/Da tenquellen_TopPlus_Open.pdf

4. Deutscher Wetterdienst (2016). Starkniederschläge in Deutschland. Deutscher Wetterdienst, Offenbach am Main, Deutschland, 4 p.

5. Dyck S. \& Peschke G (1989). Grundlagen der Hydrologie (Basics of hydrology), 2nd ed. Berlin: Verlag für Bauwesen.

6. Dyck S. \& Peschke G (1995). Grundlagen der Hydrologie (Basics of hydrology), 3rd ed. Berlin: Verlag für Bauwesen.

7. Fallmann, J., Wagner, S. \& Emeis, S (2017). High resolution climate projections to assess the future vulnerability of European urban areas to 
climatological extreme events. Theor Appl Climatol 27, pp. 667-683.

8. geomer $\mathrm{GmbH}$ (2018). Hydro ${ }^{\text {RAS: }}$ Software zur Berechnung von Abflussbeiwerten für die Starkregensimulation mit FloodArea $^{\mathrm{HPC}}$ (Anwenderhandbuch). 27 p.; Heidelberg.

9. geomer $\mathrm{GmbH}$ (2017). FloodArea ${ }^{\mathrm{HPC}}$-Desktop: ArcGIS-Erweiterung zur Berechnung von Überschwemmungsbereichen (Anwenderhandbuch). - geomer $\mathrm{GmbH} \&$ Ingenieurgemeinschaft Ruiz Rodriguez + Zeisler + Blank, 61 p., Heidelberg, Wiesbaden.

10. Landesanstalt für Umwelt, Messungen und Naturschutz Baden-Württemberg (LUBW) (2016). Leitfaden Kommunales Starkregenrisikomanagement in Baden-Württemberg. Karlsruhe, 64 p.

11. Landesamt für Vermessung, Geoinformation und Landentwicklung (LVGL), (2015). ALKISObjektartenkatalog für das Saarland (ALKIS-OK SL) www.saarland.de/dokumente/thema_lkvk2/ALKISOK-SL601_Jun_2015.pdf

12. Lutz, W. (1984). Berechnung von Hochwasserabflüssen unter Anwendung von Gebietskenngrößen. - Dissertation, Universität Karlsruhe.

13. Parrot J-F., Ramírez-Núñez C. (2015). LiDAR DTM: artefacts and corrections. Investigaciones Geograficas: Boletin, 13 p.

14. Steinbrich, A., Leistert, H., Weiler, M. (2016). Modelbased quantification of runoff generation processes at high spatial and temporal resolution. Environmental Earth Sciences Thematic Issue: Water Resources and Research in Germany.

15. Tyrna, B., Assmann, A., Fritsch, K. and Johann, G. (2018). Large-scale high-resolution pluvial flood hazard mapping using the raster-based hydrodynamic two-dimensional model FloodArea ${ }^{\mathrm{HPC}}$. J Flood Risk Management, 11: 